\title{
Impact of Three Soil Textures on the Fungal Community Structure in Rhizosphere Soils of Malus hupehensis Rehd. Seedlings
}

Haiyan Wang, Ran Chen, Yuefan Sheng, Weitao Jiang, Rong Zhang Xuesen Chen, Xiang Shen, Chengmiao Yin, and Zhiquan Mao

State Key Laboratory of Crop Biology/College of Horticultural Science and Engineering, Shandong Agricultural University, Tai'an 271018, Shandong, China

Additional index words. Apple replant disease, biomass suppression, Fusarium, highthroughput sequencing, RDA analysis

\begin{abstract}
The relationship between soil texture and the degree of apple replant disease (ARD) was analyzed from the perspective of the microbial community structure and diversity within the rhizosphere soil of Malus hupehensis Rehd. seedlings. Three different textured soils were taken from different apple orchards in Laizhou, Yantai. The soils were divided into two parts, one was kept in replanted conditions, and the other was fumigated with methyl bromide to act as a high standard control. The strength of ARD occurrence was examined by measuring fresh and dry weight suppression (\%) of the $M$. hupehensis seedlings. Differences in the fungal community structure (especially in Fusarium) among the three soil texture types were analyzed using high-throughput sequencing. The results showed that replanted loam clay soil had the highest fungal diversity, followed by sandy loam soil and finally loam soil. The richness of fungi between soil textures, however, was not significantly different. At the genus level, the relative abundance of Fusarium was $1.96 \%, 0.78 \%$, and $10.89 \%$ in replanted sandy loam, replanted loam soil, and replanted loam clay soil, respectively. Moreover, the gene copy number of Fusarium oxysporum, Fusarium sol$a n i$, and the inhibition rate of fresh weight of $M$. hupehensis seedlings were the same in the three soil textures. The plant height, photosynthesis (net) $\left(P_{n}\right)$, and stomatal conductance $\left(g_{\mathrm{S}}\right)$ of the $M$. hupehensis seedlings were significantly less in the replanted soil compared with the control treatments, with the overall difference being greatest in replanted loam clay soil, followed by replanted sandy loam and then replanted loam soil.
\end{abstract}

Most of the main apple-producing areas face continuous cropping obstacles when replacing old orchards, due to a shortage of land resources (Mazzola and Manici, 2012; Yin et al., 2017). ARD results from a combination of multiple factors (Tewoldemedhin et al., 2011a), but is mainly believed to occur

Received for publication 12 Jan. 2021. Accepted for publication 6 Mar. 2021.

Published online 30 April 2021.

The research was supported by an earmarked fund for National Modern Agro-industry Technology Research System of China (CARS-27), the National Natural Science Foundation of China (32072510), Shandong Agricultural Major Applied Technology Innovation Project (SD2019ZZ008); Taishan Scholar Funded Project (NO.ts20190923); Qingchuang Science and Technology Support Project of Shandong Colleges and Universities (2019KJF020); Fruit innovation team in Shandong Province, China (SDAIT-06-07)

C.Y. and Z.M. are the corresponding authors. E-mail: mzhiquan@sdau.edu.cn or yinchengmiao@163.com.

This is an open access article distributed under the CC BY-NC-ND license (https://creativecommons. org/licenses/by-nc-nd/4.0/). due to an imbalance in the soil microbial structure and an accumulation of harmful microorganisms (Tewoldemedhin et al., 2011a); however, the types of harmful fungi in different regions vary (Manici et al., 2003; Mazzola et al., 2009; Tewoldemedhin et al., 2011b), with studies finding that Fusarium is one of the main harmful fungi causing ARD in the Bohai Bay area in China (Wang et al., 2018a). In addition, differences in the physical and chemical properties of soil also have an important impact on soil microbial activity (Gupta, et al., 2017). Soil texture is a particularly important physical property, as it plays an important role in the supply of nutrients and maintaining the soil environmental conditions (Plante et al., 2006). Previous studies have shown that soil texture may have an important relationship with the degree of ARD (Franke-Whittle et al., 2018).

The random combination of different sized mineral particles in soil constitutes different soil textures. This difference in texture impacts the mechanical resistance and porosity of the soil, and thereby, the exchange of water, fertilizer, and heat within the soil. These physical differences affect the growth and development of plants and microorganisms (Long et al., 2017; Zeng, 2014). Masoni et al. (2007) found that the nitrogen and phosphorus absorption, dry matter accumulation, and yield of wheat plants within clay loam conditions were significantly higher than those in sandy loam soil. Too many clay particles, however, made the soil aeration poor and reduced root vitality and growth (Jia et al., 2013). Moreover, different soil textures can lead to different soil microbial species (Yan, 2011) and phenolic acid content (Viator et al., 2006). Loam soil has been shown to have the highest microbial activity, and clay soil the lowest (Cai et al., 2003). The content of bacteria, actinomycetes, and total microorganisms in loam soil is higher than in sandy soil, whereas fungi are the most abundant in clay (Yan, 2011). Wang and $\mathrm{Hu}$ (2014) found that the more sand particles there are in the soil, the smaller the powder particles and the lower the content of phenolic acids. In addition, Felix et al. (2018) found that sand soil exhibited the most serious occurrence of ARD, whereas silt loam soil showed the least ARD.

There are few reports on the microbial community structure of different soil textures. This article intends to use that as an entry point to focus on the differences in the fungal community structure (especially in the harmful genus of Fusarium) within different replanted soil textures, to analyze the biological factors causing varying degrees of ARD in different textured soils. This work provides a theoretical basis for exploring the relationship between soil texture and ARD.

\section{Materials and Methods}

Experimental materials and design. From Mar. to Oct. 2018, the experiment was conducted at Shandong Agricultural University. The soil for the experiment was taken from three 25-year-old apple orchards (Dashaling, Fengmaozhai, Wantou Village) in Yantai, Shandong. M. hupehensis Rehd. seedlings were used as test materials. Following the US soil classification standard, the micropipette method was used to determine the soil texture, which showed that the soil in Dashaling was sandy loam, Fengmaozhai was loam, and Wantou village was clay loam. The soil samples within the three different soil texture groups were divided into two treatments: replanted soil and methyl bromide fumigation soil (as a high standard control). The three soil texture groups are abbreviated throughout this article as replanted sandy loam soil (SL), replanted loam soil (FL), and replanted clay loam soil (WL). The physical and chemical properties of the three soil textures are shown in Table 1.

When the M. hupehensis seedlings had six true leaves, healthy seedlings were chosen and transplanted into a mud pot containing $7.0 \mathrm{~kg}$ of test soil. Two seedlings were planted per pot, and each pot received the same fertilizer and water management regimen. Destructive sampling in mid-Aug. 2018 was done to examine the differences in 
Table 1. Basic characteristics of the test soil.

\begin{tabular}{|c|c|c|c|c|c|c|}
\hline Soil type & $\mathrm{pH}(\mathrm{mg} / \mathrm{kg})$ & TOC $(\mathrm{g} / \mathrm{kg})$ & $\mathrm{NO}_{3}{ }^{-}-\mathrm{N}(\mathrm{mg} / \mathrm{kg})$ & $\mathrm{NH}_{4}{ }^{+}-\mathrm{N}(\mathrm{mg} / \mathrm{kg})$ & $\mathrm{AP}(\mathrm{mg} / \mathrm{kg})$ & $\mathrm{AK}(\mathrm{mg} / \mathrm{kg})$ \\
\hline$\overline{\mathrm{SL}}$ & $7.05 \pm 0.04 \mathrm{a}$ & $10.88 \pm 0.48 \mathrm{c}$ & $0.93 \pm 0.14 \mathrm{c}$ & $13.79 \pm 0.35 \mathrm{a}$ & $13.87 \pm 1.64 \mathrm{a}$ & $173.28 \pm 6.03 \mathrm{c}$ \\
\hline FL & $6.91 \pm 0.09 \mathrm{a}$ & $16.02 \pm 0.10 \mathrm{~b}$ & $2.25 \pm 0.10 \mathrm{a}$ & $10.78 \pm 0.06 b$ & $16.01 \pm 1.84 \mathrm{a}$ & $208.38 \pm 6.03 b$ \\
\hline WL & $7.04 \pm 0.06 \mathrm{a}$ & $17.76 \pm 0.37 \mathrm{a}$ & $1.75 \pm 0.09 \mathrm{~b}$ & $10.70 \pm 0.07 b$ & $10.93 \pm 1.06 \mathrm{~b}$ & $439.05 \pm 8.84 \mathrm{a}$ \\
\hline
\end{tabular}

$\overline{\mathrm{TOC}}=$ total organic carbon; $\mathrm{AP}=$ available phosphorus; $\mathrm{AK}=$ available potassium; $\mathrm{SL}=$ replanted sandy loam soil; FL $=$ replanted loam soil; WL $=$ replanted clay loam soil. Data are mean \pm SD (standard deviation). Different lowercase letters in the same column indicate a significant difference at $P<0.05$ level by Duncan's new multiple range test.

seedling characteristics and the microbial community structure among the three different soil textures. Impurities were removed from the rhizosphere of $M$. hupehensis seedlings to obtain samples of the rhizosphere soil. The soil samples were mixed and divided into two portions: one portion was frozen at $-80^{\circ} \mathrm{C}$ for soil microbial analysis, and the other portion was kept in a refrigerator at $4{ }^{\circ} \mathrm{C}$.

Experimental methods. The plant height and stem diameter of the $M$. hupehensis seedlings were measured with a ruler and a vernier caliper respectively.

Dry and fresh weights of $M$. hupehensis seedlings were measured with an electronic balance. The degree of ARD was calculated as follows:

Fresh weight suppression

$=($ fresh weight of sterilized soil

- fresh weight of replanted soil)/

fresh weight of replanted soil $\times 100 \%$

Dry weight suppression

$=($ dry weight of sterilized soil

- dry weight of replanted soil)/

dry weight of replanted soil $\times 100 \%$

A SPAD-502 portable chlorophyll meter (Minolta, Tokyo, Japan) was used to determine the relative chlorophyll content of the fifth to seventh (from the bottom) fully expanded healthy adult leaves of the M. hupehensis seedlings. The leaf area was measured with an LI3050C (Hyashi Dienko, Tokyo, Japan). The $\mathrm{P}_{\mathrm{n}}$ and $g_{\mathrm{S}}$ of $M$. hupehensis seedlings were measured using a CIRAS-3 portable photosynthetic instrument (PP System, Amesbury, MA).

Soil chemical properties were determined following the protocol from Wang et al. (2018b). Soil pH (water: soil $=2.5: 1$ ) was measured with a PHSJ-3F pH meter (INESA, Shanghai, China). Soil organic matter was determined following the methods outlined in Bao (2000).

$$
\begin{aligned}
& \mathrm{TOC}(\mathrm{g} / \mathrm{kg})=\left[\mathrm{C}_{\mathrm{FeSO} 4} *\left(\mathrm{~V}_{\text {control }}-\mathrm{V}_{\text {treatment }}\right)\right.
\end{aligned}
$$

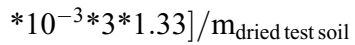

$$
\begin{aligned}
& \times 1000 * 1.724 \\
& \mathrm{NO}_{3}{ }^{-}-\mathrm{N}(\mathrm{mg} / \mathrm{kg})=\mathrm{C}_{\text {treatment }}(\mu \mathrm{g} / \mathrm{ml})^{*} \\
& \mathrm{~V}_{\text {extract }} * \text { ts } / \mathrm{m}_{\text {test soil }} \\
& \mathrm{NH}_{4}{ }^{+}-\mathrm{N}(\mathrm{mg} / \mathrm{kg})=\mathrm{C}_{\text {treatment }}(\mu \mathrm{g} / \mathrm{ml})^{*} \\
& \mathrm{~V}_{\text {extract }} * \text { ts } / \mathrm{m}_{\text {test soil }} \\
& \mathrm{AP}(\mathrm{mg} / \mathrm{kg})=[\rho(\mu \mathrm{g} / \mathrm{ml}) * 50 * \mathrm{ts} / \\
& \left.\left(\mathrm{m}_{\text {dried test soil }} * 10^{3}\right)\right] \times 1000
\end{aligned}
$$

Table 2 . The degree of severity of apple replant disease within the test soil.

\begin{tabular}{lcc}
\hline Sample name & Fresh wt suppression (\%) & Dry wt suppression (\%) \\
\hline SL & 137.05 & 116.90 \\
FL & 50.48 & 54.10 \\
WL & 145.28 & 141.53 \\
\hline
\end{tabular}

$\overline{\mathrm{SL}}=$ replanted sandy loam soil; $\mathrm{FL}=$ replanted loam soil; $\mathrm{WL}=$ replanted clay loam soil.

$$
\begin{aligned}
\mathrm{AK}(\mathrm{mg} / \mathrm{kg})= & \mathrm{C}_{\text {treatment }}(\mu \mathrm{g} / \mathrm{ml})^{*} \\
& \mathrm{~V}_{\text {extract }} / \mathrm{m}_{\text {dried test soil }}
\end{aligned}
$$

The gene copy number of $F$. oxysporum and $F$. solani in the soil was determined following the methods of Wang (2018).

$$
\begin{aligned}
& \text { The gene copy number of } F \text {. oxysporum } \\
& =\left\{10^{\wedge}[\mathrm{ct}-36.396 /(-2.291)]\right. \\
& \quad * 9.1212\} / 2801 \times 10^{11}
\end{aligned}
$$

The gene copy number of $F$. solani

$=\left\{10^{\wedge}[\mathrm{ct}-26.941 /(-2.352)]\right.$

$* 9.1212\} / 2801 \times 10^{11}$

(Note: Standard curve of $F$. oxysporum: $R^{2}=0.993, \mathrm{y}=-2.291 \mathrm{x}+36.396$; Standard curve of $F$. solani: $R^{2}=0.994$, $\mathrm{y}=-2.352 \mathrm{x}+26.941)$

The E.Z.N.A. soil DNA extraction kit (Omega Bio-Tek, Norcross, GA) was used to extract DNA. The primers for fungi were ITS1 (F: 5'-AACCTGCGGAAGGATCATT-3'; R: 5'-GARCCAAGAGATCCRTTG-3'). The adapters were merged, polymerase chain reaction amplification was performed, and the final product was purified. The sequencing library was constructed after quantification and homogenization. After passing the quality inspection, the library was mixed and denatured and added to the Illumina $\mathrm{Mi}$ Seq sequencing platform for high-throughput sequencing (Beijing Yuanyi Biotechnology Co., Ltd., Beijing, China), followed by bioinformatics analysis.

Data analysis. The UNITE taxonomy database (Release 6.0, http://unite.ut.ee/index. php) was used to conduct species annotation based on operational taxonomic units (OTUs). Alpha diversity analysis was conducted with MOTHUR (Version 1.33.2) software, using Excel (Microsoft, Redmond, WA) and R language tools (Vienna, Austria). Both the Shannon and Simpson indices were calculated to estimate the Alpha diversity. A principal component analysis using CANOCO (Version 4.54) was done to process the species composition and relative abundance data, and Excel and SPSS were used for general data processing. To detect differences between the soil texture samples, $t$ tests were performed.

\section{Results}

Analysis of the degree of $A R D$ in rhizosphere soils of different textures. By measuring the biomass of $M$. hupehensis seedlings, the degree of ARD in three different textured soils was calculated, as shown in Table 2 . The suppression of fresh weight and dry weight of $M$. hupehensis seedlings showed a trend of WL $>$ SL $>$ FL, with the suppression of fresh weight and dry weight of WL being 2.88 times and 2.62 times greater than that of SL and FL, respectively.

Analysis of the physiological index of $M$. hupehensis Rehd. seedlings grown in soils of different textures. The impact of the soil texture on the physiological index of M. hupehensis was examined by measuring the plant height, stem diameter, relative chlorophyll content, leaf area, $\mathrm{P}_{\mathrm{n}}$, and $g_{\mathrm{S}}$ of the seedlings. Plant height, $\mathrm{P}_{\mathrm{n}}$ and $g_{\mathrm{S}}$ showed large significant differences between the control treatments (where the soil was fumigated with methyl bromide) and the replanted soils of the same soil texture (Fig. 1). This trend was consistent with the suppression of fresh weight and dry weight, especially for the suppression of $g_{\mathrm{S}}$ in replanted WL, which displayed the most significant difference.

In-depth evaluation of soil sample sequencing. Internal transcribed spacer sequencing of fungi was performed on the three different textured soils. After removing lowquality, barcode, and primer sequences, three groups of nine samples were processed to obtain a total of 391,364 effective sequences. Clustering of the effective sequences displayed 1000, 808, and 1102 OTUs within the SL, FL, and WL respectively. As shown in Fig. 2, the coverage of the nine samples was above $99.99 \%$, indicating that the sequencing depth had covered most of the species in the sample, and the sequencing results were reasonable.

Random sampling of the sequences was done to construct a dilution curve based on the number of sequences drawn and the number of OTUs they represented. When the dilution curve tends to be flat, it means that the amount of sequencing data are reasonable and more data will only produce a small amount of new OTUs (Amato et al., 2013). The dilution curves of all samples are shown 


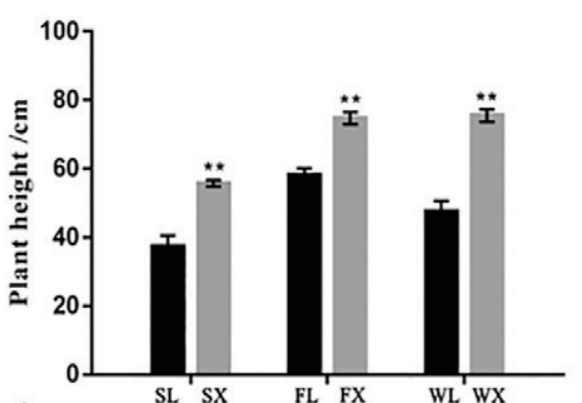

A

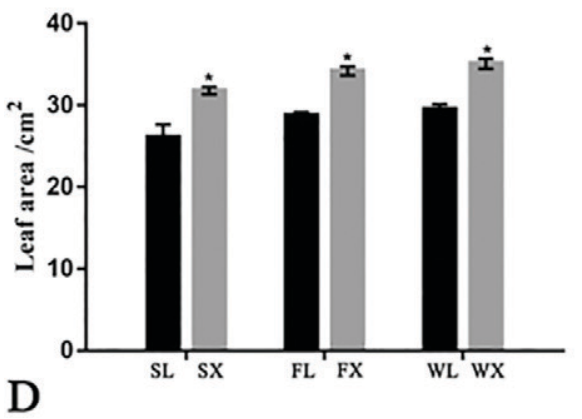

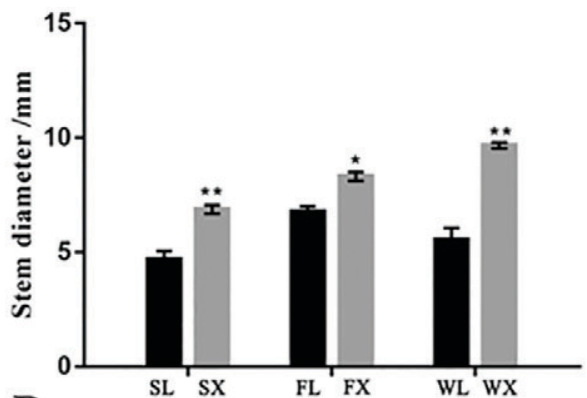

B

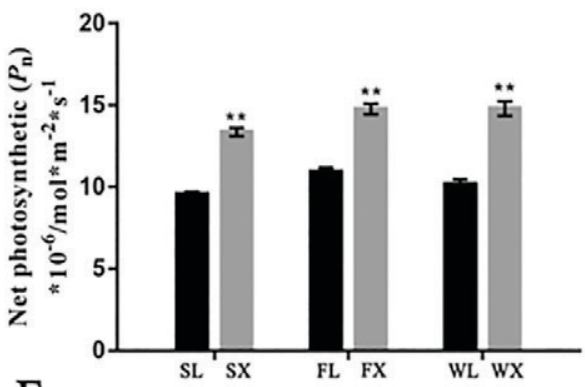

$\mathrm{E}$
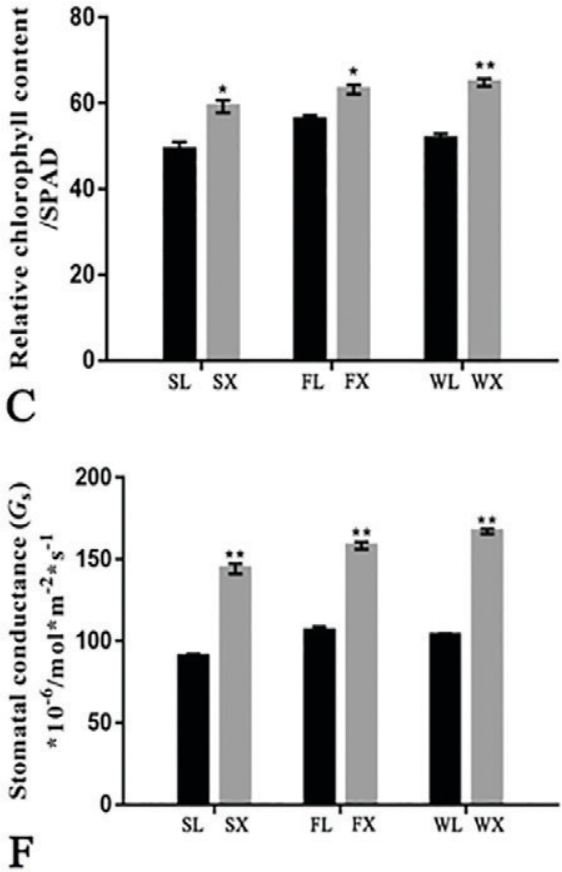

Fig. 1 Effect of different soil textures on plant height (A), stem diameter (B), relative chlorophyll content (C), leaf area (D), net photosynthetic rate $\left(\mathrm{P}_{\mathrm{n}}\right)(\mathbf{E})$, and stomatal conductance $\left(g_{\mathrm{S}}\right)(\mathbf{F})$ of Malus hupehensis Rehd. seedlings. $\mathrm{SL}=$ replanted sandy loam soil; $\mathrm{FL}=$ replanted loam soil; WL $=$ replanted clay loam soil. SX $=$ Sandy loam soil with methyl bromide fumigation; FX $=$ Loam soil with methyl bromide fumigation; WX $=$ Clay loam soil with methyl bromide fumigation. A T-test was used to determine the significance of the difference between two treatments. $*$ Above the bars represents a significant difference in the fumigation of methyl bromide treatment and the control of the same soil texture at the 0.05 level. **Indicates an extremely significant difference between the fumigation of methyl bromide treatment and the control of the same soil texture at the 0.01 level.

coverage curve

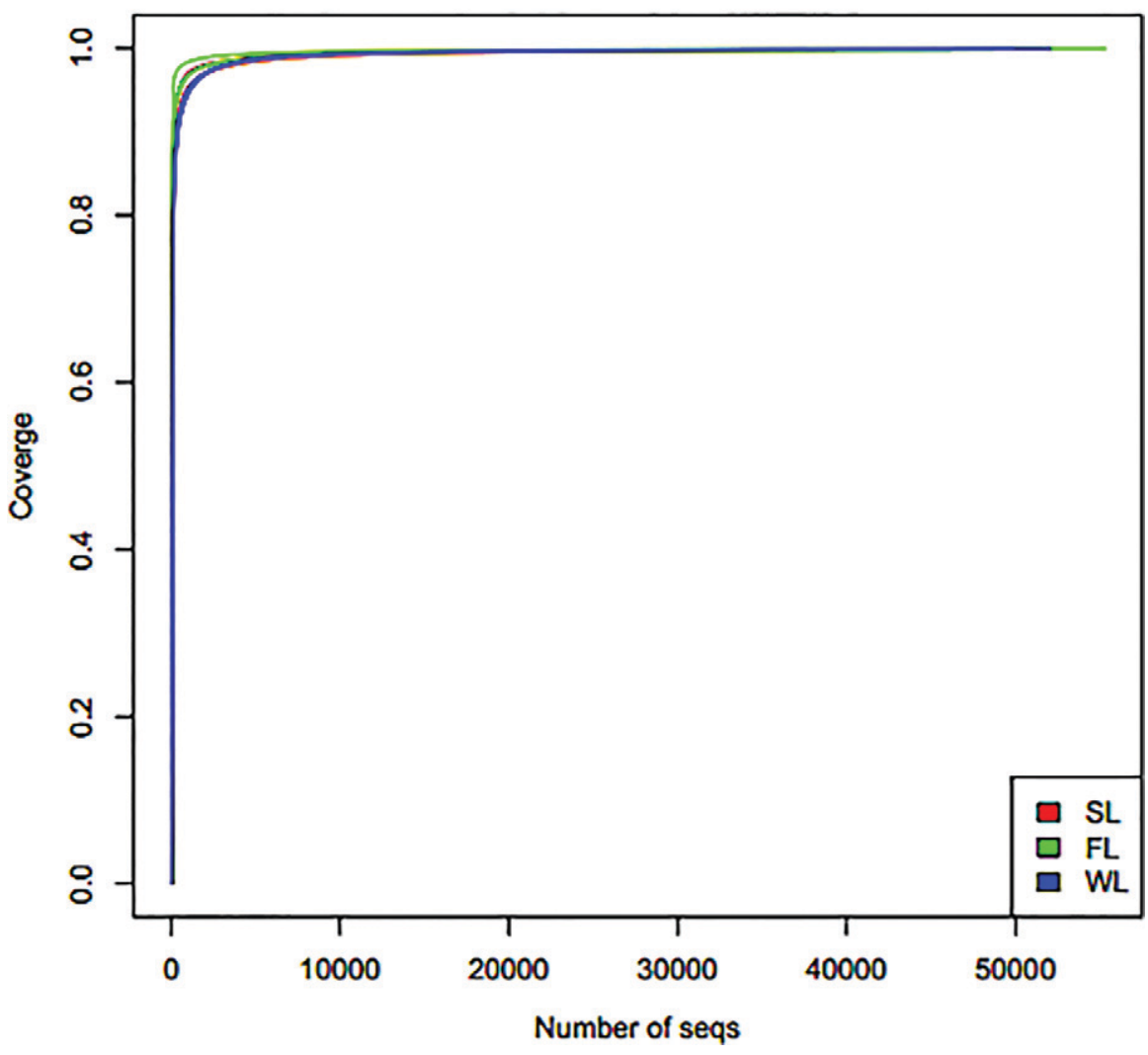

Fig. 2. Coverage curves of operational taxonomic units in different samples. SL $=$ replanted sandy loam soil; FL = replanted loam soil; WL = replanted clay loam soil. in Fig. 3. The number of OTUs in the figure tends to be flat, indicating that the amount of data were reasonable.

Evaluation of the diversity and richness of microbial communities in rhizosphere soils of different textures. The diversity within a specific area or ecosystem constitutes the Alpha diversity (Blaxter et al., 2005). The larger the Shannon index and the smaller the Simpson index, the higher the community diversity. As shown in Table 3, there were significant differences in the Shannon index of the three replanted soils. The Shannon index was the largest within WL, followed by SL, whereas FL had the smallest Shannon index. There were also significant differences in the Simpson index of the three replanted soils, of which the FL treatment had the largest Simpson index, followed by SL, and then FL. The results of the two indices were consistent, indicating that the WL soil community had the highest diversity, followed by SL and FL. The Ace index and Chaol index reflected the richness of the community (i.e., the number of fungi). There was no significant difference in the Ace index and the Chaol index of the three replanted soils, indicating that the richness of the fungal communities within the SL, FL, and WL soils was not significantly different.

Statistics of the microbial communities in rhizosphere soils with different textures at the phylum and genus levels. As can be seen from Fig. 4, the fungi within the three 
rarefaction curve

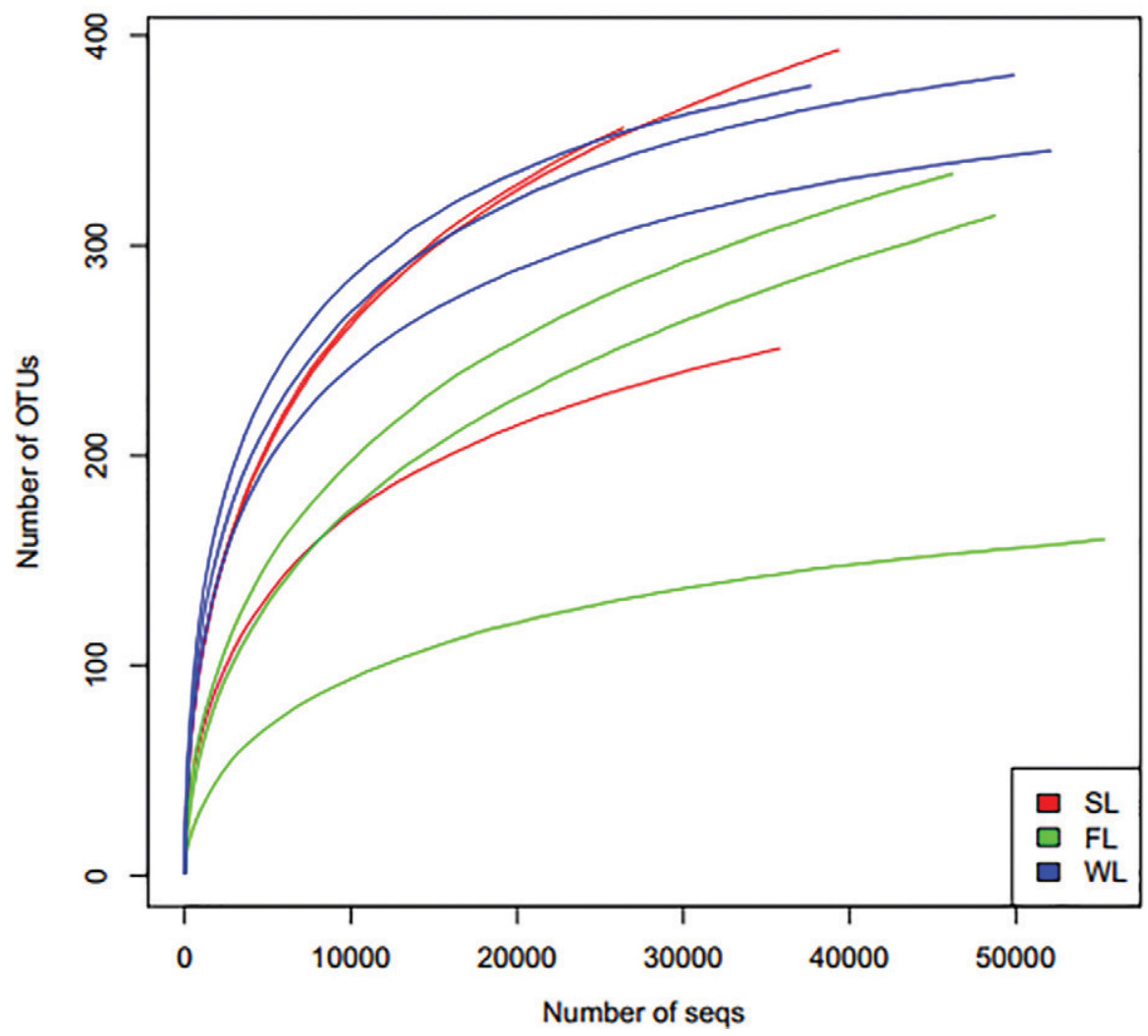

Fig. 3. Rarefaction curves of operational taxonomic units in different samples SL $=$ replanted sandy loam soil; FL = replanted loam soil; $\mathrm{WL}=$ replanted clay loam soil.

Table 3. Diversity and abundance of operational taxonomic units in replanted soils with different soil textures.

\begin{tabular}{lcccl}
\hline Sample name & Shannon index & Simpson index & Ace index & \multicolumn{1}{c}{ Chao1 index } \\
\hline SL & $2.94 \pm 0.16 \mathrm{~b}$ & $0.13 \pm 0.018 \mathrm{~b}$ & $430.78 \pm 20.80 \mathrm{a}$ & $431.17 \pm 18.83 \mathrm{a}$ \\
FL & $2.04 \pm 0.18 \mathrm{c}$ & $0.24 \pm 0.028 \mathrm{a}$ & $402.25 \pm 17.84 \mathrm{a}$ & $378.77 \pm 7.21 \mathrm{~b}$ \\
WL & $3.63 \pm 0.11 \mathrm{a}$ & $0.05 \pm 0.005 \mathrm{c}$ & $388.34 \pm 15.12 \mathrm{~b}$ & $386.92 \pm 13.36 \mathrm{ab}$ \\
\hline
\end{tabular}

$\overline{\mathrm{SL}}=$ replanted sandy loam soil; $\mathrm{FL}=$ replanted loam soil; $\mathrm{WL}=$ replanted clay loam soil. Data are mean \pm SD (standard deviation). Different lowercase letters in the same column indicate a significant difference at $P<0.05$ level by Duncan's new multiple range test.

replanted soils were mainly composed of Ascomycota, Basidiomycota, Zygomycota, and Chytridiomycota. Among them, Ascomycota and Basidiomycota were the dominant phyla in all three replanted soils. In the SL, FL, and WL, the relative abundance of Ascomycota was $41.84 \%, 58.05 \%$ and $55.97 \%$, and the relative abundance of Basidiomycota was $51.21 \%, 34.49 \%$ and $33.02 \%$, respectively.

At the genus level, 148 genera of fungi were detected in the replanted soils of different textures. Guehomyces, Pseudeurotium, Metarhizium, Penicillium, and Mortierella had the highest relative abundance within the SL soil. In the FL, Pseudeurotium, Guehomyces, Cephalotheca, Mortierella, and Fusarium were the most abundant. Guehomyces, Fusarium, Cryptococcus, Pseudeurotium, and Penicillium had the highest relative abundance in the WL. As can be seen from Fig. 5, the relative abundance of Fusarium in the fungal communities significantly differed between the replanted SL, FL, and WL soils, being $1.96 \%, 0.78 \%$, and $10.89 \%$, respectively. In summary, the abundance percentage of harmful Fusarium in WL was the largest, followed by SL, and finally FL.

Analysis of the gene copy number of $F$. oxysporum and $F$. solani in different soil textures. Determination of the gene copy number of $F$. oxysporum and $F$. solani in different soil textures was done using real-time fluorescence quantification technology. As can be seen in Fig. 6, there were significant differences among the three treatments. The gene copy number of the two Fusarium species in WL was the highest, followed by SL, and then FL. Notably, the gene copy number of $F$. solani in WL was 3.61 and 17.72 times greater than that in SL and FL, respectively.

RDA analysis of the biomass inhibition rate and environmental factors. It can be seen in Table 4 that the suppression of dry and fresh weight of $M$. hupehensis seedlings was correlated with the physical and chemical indicators of the soil. The soil $\mathrm{pH}$ and available potassium content were positively correlated with the suppression rate. The content of available phosphorus and organic nitrogen, especially nitrate, had a significant negative correlation with the suppression of dry and fresh weight of $M$. hupehensis seedlings.

\section{Discussion}

The soil texture causes differences in the exchange of water, fertilizer, gas, and heat within the soil, and thereby is closely linked to the soil environmental conditions (Zeng, 2014). The conditions within soil affect the diversity and richness of the soil microbial community, which in turn, play an important role in the healthy growth of plants (Rumberger et al., 2007; Yim et al., 2013). Recently, there has been increasing evidence that the imbalance of soil microbial fungi is closely related to the occurrence of ARD (Mazzola et al., 2009; Tewoldemedhin et al., 2011b; Wang et al., 2018a). It is, therefore, hypothesized that the degree of occurrence of ARD may be closely related to soil texture. In this study, a high-throughput sequencing method was used to analyze the fungal community structure in soils with different textures. This sequencing was combined with measures of related physiological indicators, to reveal the relationship between the occurrence of ARD and the soil texture.

Alpha diversity analysis showed that the richness of fungi in apple orchards with different soil textures in Yantai was not significant; however, there was a significant difference in fungal diversity. WL was found to have the highest fungal diversity, followed by SL and then FL (Table 3). WL also had the largest relative abundance of Fusarium (Fig. 5).

According to analyses, the soil characteristics of WL were relatively stable. Clay loam has low porosity, strong permeability and water retention (Reynolds et al., 2007), and relatively little loss of organic matter and mineral elements (Usowicz and Lipiec, 2020). This stable soil ecology has been shown to interfere with certain dominant flora (Franzluebbers et al., 1996). In addition, excessive clay content causes phenolic acid and other autotoxic substances to accumulate in the soil, which promotes the reproduction of harmful fungi such as Fusarium (Jiang et al., 2018; Zhao et al., 2009). Contrastingly, SL was the opposite. Loam has good physical and chemical properties, and suitable hydrothermal conditions, which are conducive to the existence of microbial diversity. This high soil microbial diversity inhibits the reproduction of some harmful fungi (Fusari$u m$ ), and is more conducive to the growth of plants and soil microorganisms (Sall et al., 2006; Yan, 2011). An optimal ratio of bacteria and fungi can improve the soil microbial environment and reduce ARD. The occurrence of ARD was the most serious in WL and the lowest in FL. 
A

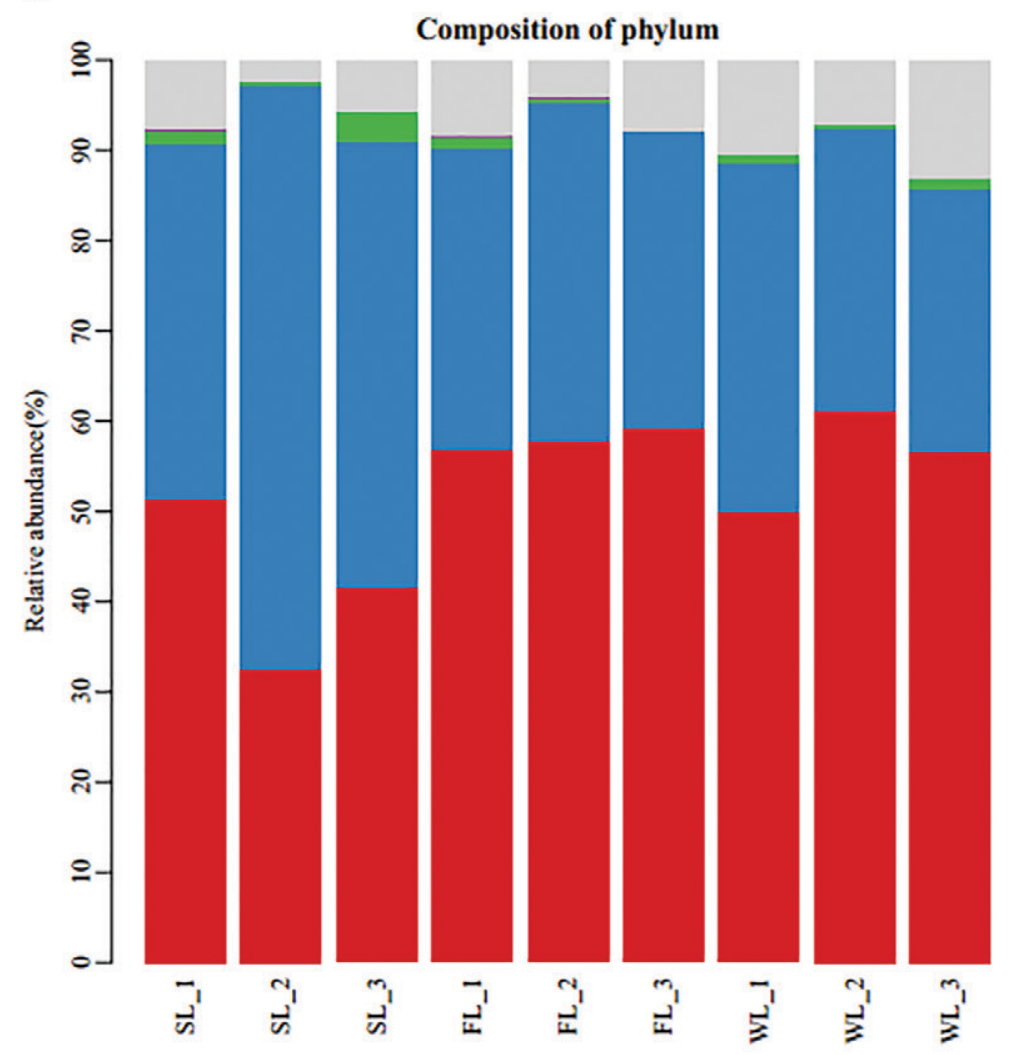

口 P_Ascomycota

a P_Basidiomycota

口 P_Zygomycota

口 P_Chytridiomycota

므unclassified_Fungi

B
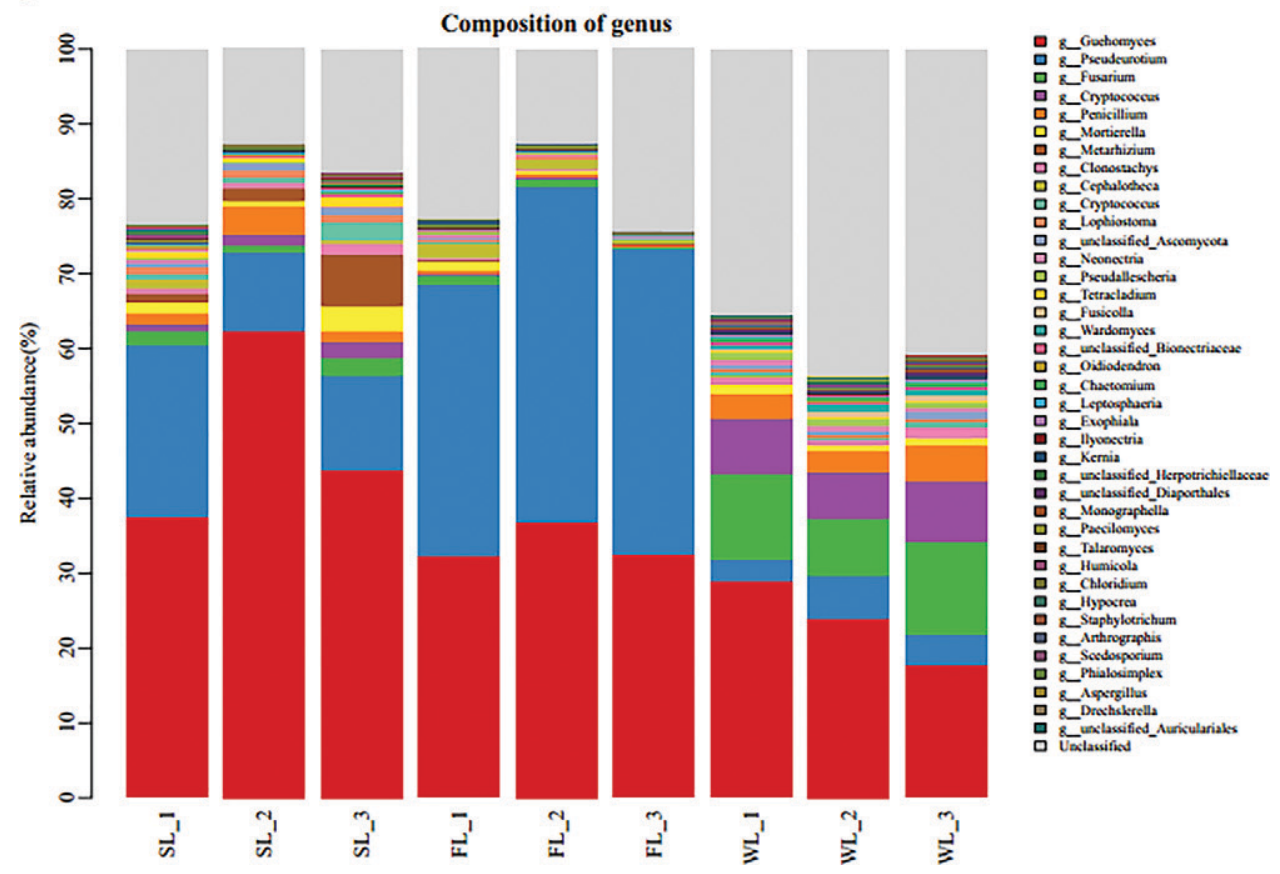

Fig. 4. Changes in relative abundance of fungal species in replanted soils of different soil textures at the level of phylum $(\mathbf{A})$ and genus $(\mathbf{B})$. SL $=$ replanted sandy loam soil; FL = replanted loam soil; $\mathrm{WL}=$ replanted clay loam soil.

There are significant differences in the fungal composition of reconstituted soils in apple orchards with different soil textures. These compositional differences indicate that different textured soils form a relatively stable dominant flora, which adapts to environmental changes but cannot change drastically in a short period (Bouskill et al., 2013; Cao et al., 2016). In this experiment, at the phylum level, in addition to unidentified fungi, the fungal communities in soil samples with different textures consisted of Ascomycetes, Basidiomycetes, Zygomycota, and Phytophthora, among which Ascomycota and Basidiomycetes were dominant (Fig. 4). The sexual reproduction period of harmful
Fusarium belongs to the phylum Ascomycota, and the number of Fusarium was positively correlated with the occurrence of ARD in Bohai Bay (Wang et al., 2018a). In addition, at the genus level, Guehomyces, Fusarium, Pseudocystis, Penicillium, and Mortierella were widely distributed in the continuous cropping soil of the three 


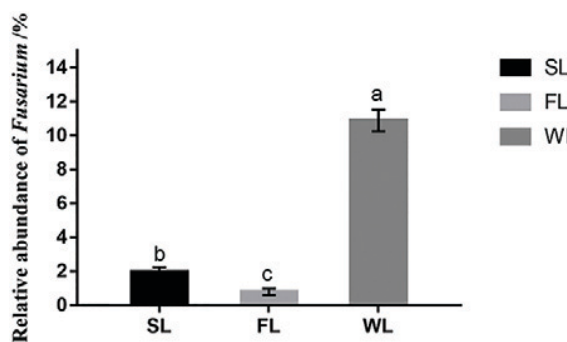

Fig. 5. Relative abundance of Fusarium in different soil textures. $\mathrm{SL}=$ replanted sandy loam soil; FL = replanted loam soil; $\mathrm{WL}=$ replanted clay loam soil. Data are mean \pm SD (standard deviation). Different lowercase letters above the bars indicate a significant difference at $P<0.05$ level by Duncan's new multiple range test.

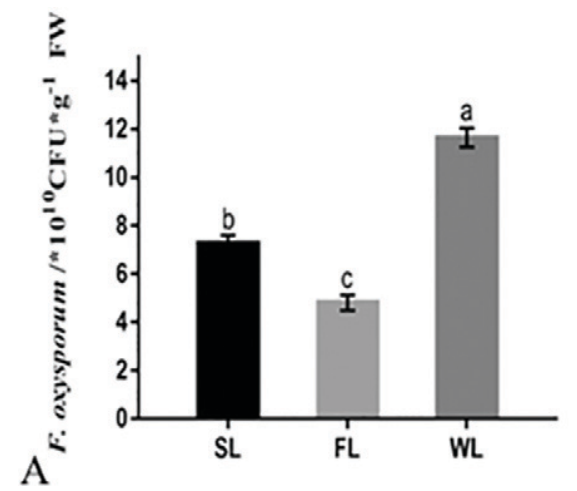

Fig. 6. The gene copy number of Fusarium oxysporum (A) and Fusarium solani (B) in different soil textures. $\mathrm{SL}=$ replanted sandy loam soil; $\mathrm{FL}=$ replanted loam soil; $\mathrm{WL}=$ replanted clay loam soil. Data are mean \pm SD (standard deviation). Different lowercase letters above the bars indicate a significant difference at $P<0.05$ level by Duncan's new multiple range test.

Table 4. Redundancy analysis of biomass inhibition rate and environmental factors.

\begin{tabular}{lcc}
\hline & Fresh wt suppression (\%) & Dry wt suppression $(\%)$ \\
\hline $\mathrm{pH}$ & 0.584 & 0.551 \\
$\mathrm{TOC}(\mathrm{g} / \mathrm{kg})$ & -0.215 & -0.029 \\
$\mathrm{NO}_{3}{ }^{-}-\mathrm{N}(\mathrm{mg} / \mathrm{kg})$ & $-0.751^{*}$ & -0.612 \\
$\mathrm{AP}$ & -0.452 & -0.533 \\
$\mathrm{AK}$ & 0.432 & 0.585 \\
\hline
\end{tabular}

$\overline{\mathrm{TOC}}=$ total organic carbon; $\mathrm{AP}=$ available phosphorus; $\mathrm{AK}=$ available potassium. $*$ Indicates significance at the 0.05 level.

regions. This fungal community was consistent with the research of Yin et al. (2014) and Roesch et al. (2007). It was found that the relative abundance of Fusarium in continuous cropping clay was the highest, reaching $10.89 \%$ (Fig. 5), and that the trend of the gene copy number of the two Fusari$u m$ species was the WL soil $>$ the SL soil $>$ the FL soil. Crucially, the gene copy number of $F$. solani in clay loam was 3.61 and 17.72 times that of SL and FL, respectively (Fig. 6). These harmful fungi severely restricted the growth of $M$. hupehensis seedlings, and compared with the fumigation and sterilization treatment, caused the maximum suppression rate of the dry and fresh weight of the plant (Table 2). These results agree with the previous research by Sheng et al. (2019), and the degree of ARD within the different textured soils has a trend of replanted WL soil $>$ replanted $\mathrm{SL}$ $>$ replanted FL soil.

Soil texture causes different degrees of apple continuous cropping obstacles. The results of the RDA analysis showed that the inhibition rate of the dry and fresh weight of $M$. hupehensis seedlings was closely related to the content of soil mineral elements (Table 4). Different soil textures have different physical and chemical properties, which can inhibit the biomass and photosynthesis of plants under continuous cropping conditions water retention properties. Good fertility and the enrichment of $\mathrm{NO}_{3}{ }^{-}-\mathrm{N}$, which resulted in the largest dry and fresh weight inhibition rate. Xu et al. (2016) found that soil environ-

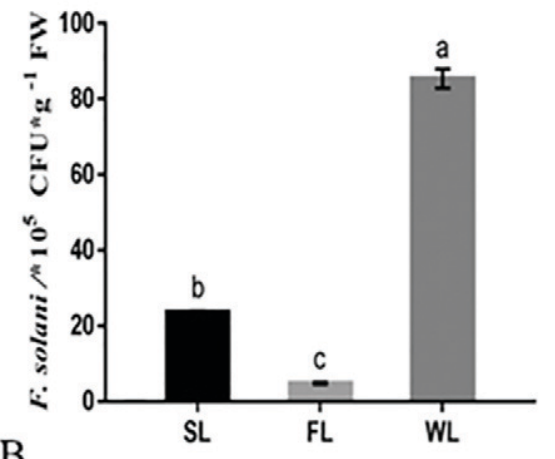

B excessive $\mathrm{NO}_{3}{ }^{-}-\mathrm{N}$ in the soil.

\section{Literature Cited}

Amato, K.R., C.J. Yeoman, A. Kent, N. Righini, F. Carbonero, A. Estrada, H.R. Gaskins, R.M. Stumpf, S. Yildirim, M. Torralba, M. Gillis, B.A. Wilson, K.E. Nelson, B.A. White, and S.R. Leigh. 2013. Habitat degradation impacts black howler monkey (Alouatta pigra) gastrointestinal microbiomes. ISME J. 7:1344-1353, doi: 10.1038/ismej.2013.16.

Bao, S.D. 2000. Soil agrochemical analysis. 3rd edition. Beijing, China Agricultural Press. (in Chinese).

Blaxter, M., J. Mann, T. Chapman, F. Thomas, C. Whitton, R. Floyd, and E. Abebe. 2005. Defining operational taxonomic units using DNA barcode data. Philos. Trans. R. Soc. Lond. B Biol. Sci. 360(1462):1935-1943, doi: 10.1098/ rstb.2005.1725.

Bouskill, N.J., H.C. Lim, S. Borglin, R. Salve, T.E. Wood, W.L. Silver, and E.L. Brodie. 2013. Pre-exposure to drought increases the resistance of tropical forest soil bacterial communities to extended drought. ISME J. 7(2):384 394, doi: 10.1038/ismej.2012.113.

Cai, Y.F., Z.W. Liao, J. Luo, and F. Li. 2003. Characteristics of disease suppression and microorganisms in different texture soils (in Chinese). J. Agro-Environment Sci. 05:553-556.

Cao, H., Y.G. Li, C.R. Zhou, L.F. Ning, and H.Q Yang. 2016. Effect of carbonized apple branches on bacterial and fungal diversities in apple root-zone soil (in Chinese). Scientia Agricultura Sinica 49(17):3413-3424, doi: 10.3864/j.issn.0578-1752.2016.17.014.

Gupta, N., S. Debnath, S. Sharma, P. Sharma, and J. Purohit. 2017. Role of nutrients in controlling the plant diseases in sustainable agriculture. Agriculturally Important Microbes for Sustainable Agriculture 9:217-262, doi: 10.1051/agro:2007051.

Franke-Whittle, I.H., M.F.D. Juárez, H. Insam, S. Schweizer, A. Naef, A.R. Topp, M. Kelderer, T. Rühmer, G. Baab, J. Henfrey, and L.M. Manici. 2018. Performance evaluation of locally available composts to reduce replant disease in apple orchards of central Europe. Renew. Agr. Food Syst. 34:543-557, doi: 10.1017/ S1742170518000091.

Franzluebbers, A.J., R.L. Haney, F.M. Hons, and D.A. Zuberer. 1966. Active fractions of organic matter in soils with different texture. Soil Biol. Biochem. 28(10/11):1367-1372, doi: 10.1016/ S0038-0717(96)00143-5.

mental factors have a certain impact on the microbial community structure, and the diversity of the microbial community is not a simple linear relationship with the degree of ARD. Therefore, it is necessary to continue carrying out corresponding field experiments and continuous observation and determination to further clarify different soils.

\section{Conclusion}

There were significant differences in microbial diversity in different soil textures. In particular, the accumulation of harmful fungi such as Fusarium disrupts the balance of the microbial community structure, and inhibits the growth of $M$. hupehensis seedlings to varying degrees. The suppression rate was found to be most severe in WL, followed by SL and FL. This trend among soil textures
Jia, L.H., C.Q. Zhao, Y.F. Wang, and M.L. Wang. 2013. Effects of different soil textures on the growth and distribution of root system and yield in peanut (in Chinese). Chinese J. Plant Ecol. 37(07):684-690, doi: 10.3724/SP. J.1258.2013.00071.

Jiang, W.T., C.M. Yin, Y.N. Duan, L. Xiang, M. Wang, X.S. Chen, X. Shen, M. Zhang, and Z.Q. Mao. 2018. Phloridzin and Fusarium moniliforme aggravated the replanted soil environment and inhibited the growth of $\mathrm{Ma}$ lus hupehensis seedlings (in Chinese). Acta Horticulturae Sinica 45(01):21-29, doi: 10.16420/j.issn.0513-353x.2017-0285.

Long, H.Y., D.J. Zhang, and J. Jin. 2017. Effects of soil textures on growth, biomass of Stylosanthes Guianensis and fertility of soils (in Chinese). Soil 49(05):1049-1052, doi: 10.13758/j.cnki.tr.2017.05.028.

Felix, M., S. Margaux, L. Eva, P. Stefan, W. Andreas, and W. Traud. 2018. Induction and diagnosis 
of apple replant disease (ARD): A matter of heterogeneous soil properties? Scientia Hort. 241: 167-177, doi: 10.1016/j.scienta.2018.06.076.

Manici, L.M., C. Ciavatta, M. Kelderer, and G. Erschbaumer. 2003. Replant problems in South Tyrol: Role of fungal pathogens and microbial population in conventional and organic apple orchards. Plant Soil 256:315-324, doi: 10.1023/A:1026103001592.

Masoni, A., L. Ercoli, M. Mariotti, and I. Arduini. 2007. Post-anthesis accumulation and remobilization of dry matter, nitrogen and phosphorus in durum wheat as affected by soil type. Eur. J. Agron. 26(3):179-186, doi: 10.1016/j.eja.2006.09.006.

Mazzola, M., J. Brown, X. Zhao, A.D. Izzo, and G. Fazio. 2009. Interaction of brassicaceous seed meal and apple rootstock on recovery of Pythium spp. and Pratylenchus penetrans from roots grown in replant soils. Plant Dis. 93:5157, doi: 10.1094/PDIS-93-1-0051.

Mazzola, M. and L.M. Manici. 2012. Apple replant disease: Role of microbial ecology in cause and control. Annu. Rev. Phytopathol. 50:45-65, doi: 10.1146/annurev-phyto-081211-173005.

Plante, A.F., R.T. Conant, C.E. Srewant, K. Paustian, and J. Six. 2006. Impact of soil texture on the distribution of soil organic matter in physical and chemical fractions. Soil Sci. Soc. Amer. J. 70(1):287-296, doi: 10.2136/sssaj2004.0363.

Reynolds, D., C. Drury, X.M. Yang, C.A. Fox, C. Tan, and T.Q. Zhang. 2007. Land management effects on the near-surface physical quality of a clay loam soil. Soil Tillage Res. 96(1-2): 316-330, doi: 10.1016/j.still.2007.07.003.

Roesch, L.F., R.R. Fulthorpe, A. Riva, G. Casella, A.K. Hadwin, A.D. Kent, S.H. Daroub, F.A. Camargo, W.G. Farmerie, and E.W. Triplett. 2007. Pyrosequencing enumerates and contrasts soil microbial diversity. ISME J. 1(4):283-290, doi: 10.1038/ismej.2007.53.

Rumberger, A., I.A. Merwin, and J.E. Thies. 2007. Microbial community development in the rhizosphere of apple trees at a replant disease site. Soil Biol. Biochem. 39(7):1645-1654, doi: 10.1016/j.soilbio.2007.01.023.

Sall, S.N., D. Masse, N.Y.B. Ndour, and J.L. Chotte. 2006. Does cropping modify the decomposition function and the diversity of the soil microbial community of tropical fallow soil? Appl. Soil Ecol. 31(3):211-219, doi: 10.1016/j.apsoil.2005.05.007.

Sheng, Y.F., H.Y. Wang, H.Y. Qiao, M. Wang, X.S. Chen, X. Shen, C.M. Yin, and Z.Q Mao. 2019. Effects of different soil textures on the degree of replanted disease of Malus hupehensis Rehd. (in Chinese). Scientia Agricultura Sinica 52(04):715-724, doi: 10.3864/j.issn.0578-1752.2019.04.012.

Tewoldemedhin, Y.T., M. Mazzola, W.J. Botha, C.F.J. Spies, and A. McLeod. 2011b. Characterization of fungi (Fusarium and Rhizoctonia) and oomycetes (Phytophthora and Pythium) associated with apple orchards in South Africa. Eur. J. Plant Pathol. 130:215-229, doi: 10.1007/ s10658-011-9747-9.

Tewoldemedhin, Y.T., M. Mazzola, I. Labuschagne, and A. McLeod. 2011a. A multi-phasic approach reveals that apple replant disease is caused by multiple biological agents, with some agents acting synergistically. Soil Biol. Biochem. 43: 1917-1927, doi: 10.1016/j.soilbio.2011.05.014.

Usowicz, B. and J. Lipiec. 2020. The effect of exogenous organic matter on the thermal properties of tilled soils in Poland and the Czech Republic. J. Soils and Sediments 20:365-379, doi: 10.1007/s11368-019-02388-2.

Viator, R.P., R.M. Johnson, C.C. Grimm, and E.P. Richard. 2006. Allelopathic, autotoxic and hermetic effects of postharvest sugarcane residue. Agron. J. 98(6):1526-1531, doi: 10.2134/ agronj2006.0030.

Wang, G.S. 2018. Studies on fungal community in replanted soil around Bohai Gulf and alleviation apple replanted diseases by mixed cropping with Allium fistulosum L. (in Chinese). Shandong Agricultural University, Tai'an, PhD Diss.

Wang, G.S., C.M. Yin, F.B. Pan, X.B. Wang, L. Xing, Y.F. Wang, J.Z. Wang, C.P. Tian, J. Chen, and Z.Q. Mao. 2018a. Analysis of the fungal community in apple replanted soil around Bohai Gulf. Hort. Plant J. 4(05):175181, doi: 10.1016/j.hpj.2018.05.003.

Wang, G.W., B.C. Chen, G.P. Wang, H.H. Li, H. Liang, H.M. Zhou, and J.Q. Chen. 2018 b.
Study on fertilizer efficiency of superfine phosphorus and potassium activator fertilizer on Pakchoi (in Chinese). J. Soil Water Conserv. 32(04):315-320+326, doi: 10.13870/j.cnki. stbcxb.2018.04.050.

Wang, M.L. and G.R. Hu. 2014. Phenol content and its relationships with carbon and nitrogen in several agricultural soils in Hubei Province (in Chinese). China J. Agro-Environment Sci. 33(04):702-707, doi: 10.11654/ jaes.2014.04.012.

Xu, H.M., F.F. Ni, T.J. Song, X.F. Yuan, and J.H. Zhu. 2016. Fungal interannual changes in the rhizosphere soil of Paeonia lactiflora by 454 pyrosequencing (in Chinese). J. Zhejiang Chinese Medical Univ. 40(12):942-947, doi: 10.16466/j.issn1005-5509.2016.12.019.

Yan, Y.W. 2011. Effects of microorganism's population, enzyme activity on tobacco quality of differently textured soil. Hunan Agricultural University, Hunan, Master's Thesis (in Chinese).

Yim, B., K. Smalla, and T. Winkelmann. 2013. Evaluation of apple replant problems based on different soil disinfection treatments-links to soil microbial community structure? Plant Soil 366:617-631, doi: 10.1007/s11104-012-1454-6.

Yin, C.M., G.S. Wang, Y.Y. Li, X.S. Chen, S.J. Wu, and Z.Q. Mao. 2014. Assessment of fungal diversity in apple replanted orchard soils by T-RFLP analysis (in Chinese). Acta Ecologica Sinica 34(04):837-846., doi: 10.5846/ stxb201306241765.

Yin, C.M., M. Wang, J.Y. Wang, X.S. Chen, X. Shen, M. Zhang, and Z.Q. Mao. 2017. The research advance on apple replant disease (in Chinese). Acta Horticulturae Sinica 44(11):2215-2230, doi: 10.16420/j.issn.0513-353x.2017-0524.

Zeng, Y. 2014. The effect of nitrogen and soil textures on the roots of tea plants (Camellia sinensis) (in Chinese). Sichuan Agricultural University, Sichuan, Master's Thesis.

Zhao, X.L., X.H. Liu, J.Z. He, C.X. Wan, M.F. Gong, and L.L. Zhang. 2009. Effects of cotton root exudates on available soil nutrition, enzyme activity and microorganism quantity (in Chinese). Acta Botanica Boreali-Occidentalia Sinica 29(7):1426-1431. 